\title{
Crocodile tears syndrome
}

\author{
Ivan Adamec ${ }^{1} \cdot$ Mario Habek ${ }^{1,2}$
}

Received: 20 November 2015 / Accepted: 25 December 2015/Published online: 18 January 2016

(C) Springer-Verlag Berlin Heidelberg 2016

\begin{abstract}
A 39-year-old female presented with excessive tearing while eating. A year earlier she developed bilateral facial palsy due to neurosarcoidosis and the deficit persisted despite immunosuppressive treatment. Schrimer's test in the resting position was $1 \mathrm{~mm}$ on the left and $3 \mathrm{~mm}$ on the right eye (normal values $>10 \mathrm{~mm}$ ) (Fig. 1). During eating (Fig. 2) it was $15 \mathrm{~mm}$ on the left and $10 \mathrm{~mm}$ on the right eye, demonstrating gustatory hyperlacrimation.
\end{abstract}

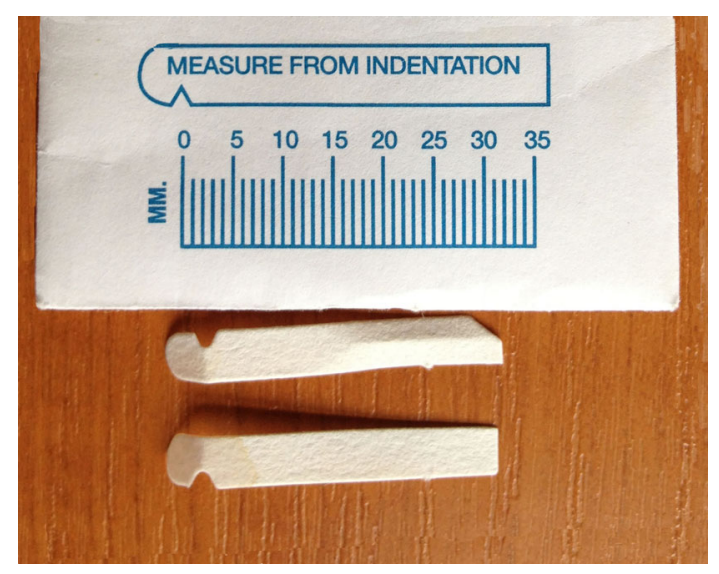

Fig. 1 Schrimer's test in the resting position

Mario Habek

mhabek@mef.hr

1 Department of Neurology, University Hospital Center Zagreb, Referral Center for Autonomic Nervous System Disorders, Kišpatićeva 12, HR-10000 Zagreb, Croatia

2 Department of Neurology, School of Medicine, University of Zagreb, Zagreb, Croatia

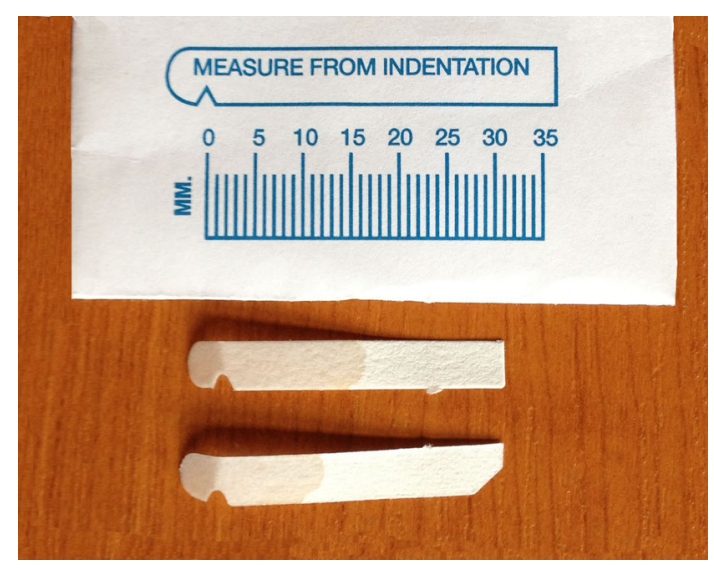

Fig. 2 Schrimer's test during eating

Crocodile tears syndrome is a rare symptom known to occur after facial nerve palsy. The presumed pathophysiological mechanism is misdirected nerve regeneration or artificial synapse forming following nerve injury [1].

\section{Compliance with ethical standards}

Conflict of interest Dr. Adamec reports no disclosures. Dr. Habek reports no disclosures.

Source of funding None other than the author's own institution.

\section{Reference}

1. Sadjadpour K (1975) Postfacial palsy phenomena: faulty nerve regeneration or ephaptic transmission? Brain Res 95:403-406 